\title{
CMaps, Learning Objects and a Blended Learning Signals \& Systems Course
}

\author{
http://dx.doi.org/10.3991/ijep.v4i5.3533 \\ A.M.B. Pavani, Member IEEE \\ Pontifícia Universidade Católica do Rio de Janeiro, Rio de Janeiro, Brazil
}

\begin{abstract}
Learning Objects (LOs) are one of building blocks of Information and Communication Technology (ICT) supported learning. ICT support can be used in the traditional face-to-face model, in a completely online situation or in a hybrid (blended) style.
\end{abstract}

The development of LOs is time and resources consuming, for this reason, it is important that they can de shared and reused. This paper addresses the use o Concept Maps (CMaps) to model topics that make up the area known as Linear Time-Invariant Systems (LTI Systems) as taught in some engineering curricula. The CMaps are used to define the granularity of Learning Objects (LOs) in this area.

It also addresses the deployment of a Blended Learning Signals and Systems course that is mandatory in five undergaduate curricula. The CMaps are used to define "regions" of related LOs that are used in the guide (story board) of this course. The LOs are among the digital resources to be used.

The results of this work allow future extensions in terms of examining the syllabi of the undergraduate courses that teach LTI Systems and of developing additional blended learning courses. Results are presented and future developments are also considered.

Index Terms - Blended Learning, Concept Maps, Learning Objects, Linear Time-Invariant Systems, Signals \& Systems.

\section{INTRODUCTION}

\section{A. Three Important Definitions}

The title of this article contains three important expressions. Each one is introduced in this section.

CMaps were created by Joseph D. Novak and his team at Cornell University (http://www.cornell.edu/) in the 1970s. A current work that presents CMaps in detail and also indicates examples of use [1] was taken as a reference to this work. In [1] there are two points worth mentioning.

The first is their definition. CMaps are ways of organizing and representing knowledge using graphical tools. They are composed of boxes (or sometimes circles or ellipses) that contain concepts. Concepts are linked to one another by lines associated with words - linking phrases or linking words - that express the relationships between two concepts. CMaps are hierarchical with the most inclusive (more general) concepts on the top and the most specific (less general) ones in the lower parts of the graph. There can also exist cross-links, i..e, links connecting concepts in different domains (segments) of a CMap. A CMap can have large branches - the domains or segments.

The second important point is that the authors suggest that before a CMap is created, the objective of the organization of knwoledge must clearly be defined or why a Cmap is being created. They call it the focus question to be answered; it yields the context of the knowledge in the map.

Learning Objects (LOs) are defined by the IEEE LTSC - Institute of Electrical and Electronics Engineers Learning Technology Standards Committee [2] as: "any entity, digital or non-digital, which can be used, re-used or referenced during technology supported learning". In this work, only digital LOs are considered.

Blended Learning is defined in [3] as: "courses that combine face-to-face classroom instruction with online learning and reduced classroom contact hours (reduced seat time)". It is important to emphasize that this definition implies in reduced seat time and this is exactly the meaning in the context of this work. Blended learning is also called hybrid learning.

\section{B. Motivation}

The identification of high attrition rates among students of two undergraduate courses that are core to engineering curricula led to different actions by the faculty who teach the courses. One was the development of Learning Objects (LOs) in an attempt to enhance the learning process. At first, the decision on which objects to be created was based on the experience of the faculty members who are involved with the actions.

LOs must be shared and reused so that the resources necessary for their development yield the most benefit. For this reason, the definition of the scope of a LO, its granularity, can be made based on a more "scientific" way. This does not mean that faculty experience and intuition are to be neglected; they may be used to check and to "polish" results.

The author decided to use Concept Maps (CMaps) as the tool to define the granularity of LOs. Granularity is of paramount importance in the reuse of LOs. If the "grains" are too big, topics may be added that are not necessary, if the are to small, too many "grains" must be used and more managing work is required.

The use of CMaps by the author of this work started with Linear Time-Invariant Systems (LTI Systems) that are the main focus of the two courses with high attrition rates - Signals \& Systems and Electric \& Electronic 
Circuits. At the same time, there is a third course that is based on this subject; it is Controls \& Servomechanisms. This is the first course in control systems and deals with LTI Systems. The focus question was the granularity of the LOs to be developed.

The first two sets of results of the use of CMaps to define LOs on LTI Systems were addressed in previous works $[4,5]$. The first work presented preliminary results that yielded insight to keep working; some mistakes were identified and corrected. The corrections and some enhancements were presented in the second.

Three possible extensions were identified: (1) the design of the structure of online courseware to fulfill the needs of courses or part of them - this can be done by creating the "story boards" or "guides" that link the LOs and other contents; (2) the analysis of LTI Systems subject in Electrical and Controls \& Automation Engineering curricula at PUC-Rio and, as consequence; (3) the definition of the corresponding courses syllabi. The curriculum of Mechanical Engineering must be examined too since it has courses on Control Systems that address LTI Systems.

\section{This Work}

This work addresses three topics. The first is a summary of the CMaps created for LOs in LTI Systems, as published in [5] with enhancements that were made afterwards; this is in section II. The second topic is a report on the development of the LOs - before using CMAps, the change in order and the current situation. The second topic also presents the regions of the CMaps where the LOs fit. Section III addresses the second topic. And last but not least, the third topic is the use of the CMaps and LOs to migrate the Signals \& Systems course from the traditional face-to-face model to blended learning. This uses extension (1) of subsection B and is presented in scetion IV. Sections V, VI and VII discuss, respectively, LOs, CMaps and the Course Guide, LOs, CMaps, and Digital Libraries, and Comments and Next Steps.

\section{A CMAP FOR LINEAR TIME-INVARIANT SySTEMS}

The current CMap for LTI Systems is the third version. Versions 1 and 2 were presented in [4] and [5]. The current CMap (v3) adds some boxes and links which are important to prepare the conceptual background for the course on Controls \& Servomechanisms. They were introduced to address all items that are important to the study of LTI Systems.

As presented in [5], it is important to observe that system properties (stability, controlability and observability) have been included but not fully represented. Concerning physical implementations, the study of Linear Circuits requires that the CMap be expanded; the same happens with systems properties.

At the moment there is not a clear decision on how to deal with these two problems (Linear Circuits and systems properties). Two options are under consideration and will examined in the near future.

Figure 1 shows the CMap (v3) for LTI Systems with the two limitations mentioned in the previous paragraphs.

In order to use LOs to create courseware, it is necessary to group them according to the topics that compose modules in different syllabi. It is important to remark that one of the objectives of defining grains of suitable sizes is the possibility that they are used in different courses.

The idea of "region" was introduced in [5]. The word was chosen to mean an area of the CMap the contains concepts and links corresponding to LOs that can be grouped to generate a module of a course. If such a module were to be supported by ICT - Information and Communication Technology, it would require a "story board" or "guide" to link the LOs and other contents, and specify the relations they hold. In a traditional face-to-face situation, the instructor would link the LOs, other contents or the topics they contain, but in an ICT supported situation, this must be accomplished through a digital content with the specific function. In the Blended Learning Signals \& Systems course this wil be addressed in section IV, there is a "story board" to be used by the students to guide their use of LOs as well as other digital contents that support the course. It will be called "guide".

The region that is used in the first module of the Signals \& Systems course is presented in section V.

\section{The CURRENT SET OF LEARNING OBJECTS}

Two faculty members who teach Signals \& Systems, Electric \& Electronic Circuits and Control \& Servomechanisms started developing LOs. The first four LOs were made available in August and early September 2012 and the choice of topics was intuitive - topics that are important in the courses. They were:

- Half-wave Rectifier - a Non Linear System

- Thévènin Equivalent Circuit

- Full-wave Rectifier - a Non Linear System

- Norton Equivalent Circuit

It quite obvious that the LOs contained topics of Electric \& Electronic Circuits, though two of them were deeply related to system classification (the two rectifiers are non linear systems and the contents of the LOs clearly address this point); they can be used in a Signals \& Systems course. They are indeed very useful to associate a concept to real electric circuits.

The next five objects were:

- Linearity

- The Mass, Spring and Damper System

- The RLC Series Circuit

- The Discrete-time Convolution

- Time-Invariance

If the nine LOs are considered, only the one on Linearity can be used in the three courses. The others can be used in two or only one. At the same time, this set can not fulfill a teaching topic in any of the courses.

For this reason, the results of the CMap (v2 and afterwards v3) started being taken into consideration to guide the new developments. The focus was the Signals \& Systems course that is the prerequisite to the other two. The next LOs to be developed and published were:

- Signals and Energy - already available

- Signals and Their Operations - already available 
- Sampling and Interpolation in the Time Domain already available

- Sampling and Interpolation in the Frequency Domain - under development

- $\mathrm{A} / \mathrm{D}$ and $\mathrm{D} / \mathrm{A}$ Conversions - under development

- Sampling and Interpolation: Aliasing - under development

- Classification of Systems According to the Nature of the Time Variables - under development

- Mono and Multivariable Systems - already available

When the four LOs under development are completed, there will a set of 19 items. Some LOs in this set allow the identication of "regions" of the CMap. This is discussed in the next section.

The topics related to sampling, interpolation, $\mathrm{A} / \mathrm{D}$ and D/A conversions and the Nyquist-Shannon Sampling Theorem had to be divided in four LOs due to large amount of contents to be presented.

The next LOs to be developed are related to timedomain models of LTI Discrete-time Systems. This is part of the second unit of the Signals \& Systems course.

It is important to remark that all LOs are published in Open Access and can be viewed by any Internet user. They can be reached by following the steps:

- Access the Maxwell (http://www.maxwell.lambda.ele.puc-rio.br)

- On the top of the home page, switch the language to English (in case it is necessary)

- On the left hand side menu, click Series

- Choose Objetos Educacionais em Engenharia Elétrica

The metadata descriptions of all LOs are both in English and Portuguese. The LOs are in Portuguese.

\section{Signals \& Systems AS A BLENDED LEARNING COURSE}

Signals \& Systems is a mandatory course in the Computer, Control \& Automation, Electrical and Nanotechnology Engineering curricula; it is also mandatory in the Computer Science curriculum. In the first three Engineering curricula it is a prerequisite for Electric \& Electronic Circuits which is the prerequisite of other courses in Electronics and Computers.

At the same time, this course has a very high percentage of students who fail - they either withdraw or get grades below the minimum required. The average percentage of students who have failed the course in the last 10 semesters ( 5 years) is $37.27 \%$. The trendline of the timeseries has a positive derivative. This is a situation that has worried faculty.

The option of changing the course to the blended learning model seemed a reasonable option.

Dziuban, Hartman and Moskal [3] point out that in blended learning students become more active and interactive learners, and, at the same time, maintain the face-to-face relationship with classmates. The authors measured and compared results in traditional face-to-face, blended and fully online courses, and results of blended courses are comparable and in some cases even better than in the traditional model. At the same time they mention additional benefits of this model to the institution, as for example an improvement in the use of classrooms.

While Dziuban, Hartman and Moskal [3] did not mention the courses in which blended learning was used at the University of Central Florida, Alonso, Manrique, Matínez and Viñes [6] presented the results of blended learning applied to a module of the 5 year Computer Engineering curriculum at the Universidad Politécnica de Madrid. This work is a good reference because: (1) it is in similar context - course of an engineering curriculum; and (2) it had a similar motivation - high failing rates among students in a mandatory and important curriculum course. The results they present indicate that the use of e-learning technology, spacifically in the blended learning model, was able to reduce the dropout rate and increase the grades of the students who took the exam.

\section{A. The Structure of the Course}

The Signals \& Systems course in the blended learning model starts next month - the first semester of 2014. It is structured in six units. Each unit is a main topic of the syllabus and is divided in smaller topics. The units are the usual in Signals \& Systems courses all over the world.

The traditional face-to-face model had four contact hours every week. The blended learning version has two contact hours and individual and/or group work will substitute for the other two.

The course runs over a 15 week school semester and the average time per topic is 2.5 weeks. Students will be able to study at their own pace but will have to take three tests after five, ten and 15 weeks. The first two units must be completed before the first test, the first four before the second and the six units for the third one.

\section{B. Course Contents}

The are different course contents for students to use some printed and most in digital format. The ones in digital format can be grouped in two sets - the first is of contents that can be downloaded and studied offline, and the second contains objects that offer interaction and, in some cases, access to the Maxwell System database, thus must be used online.

The first type content is the text book - the same that has been used for the traditional model. It has been used in the print version. The same happens to another book that is a reference. A third book [7] is in digital digital format and available in Open Access as a pdf file that can be downloaded.

The second type of content is a set of three volumes of class notes available in pdf files that can be downloaded. They address the same topics as the texts books but add alternative views and examples.

The third type is a set of contents whose objective is to offer students a guided way to exercise on the topics exercises to be solved using MATLAB ${ }^{\circledR}$, exercises to be conventionally solved, and exercises that are presented with theoretical considerations. All are in pdf files and can be downloaded. 
The fourth type is the Interactive Book in Signals and Systems. This is a set of interactive exercises organized in chapters according to the traditional structure of a Signals \& Systems course. Currently, the book makes available 167 exercises, each one with at least three sets of functions/parameters; a set is randomly selected when the exercise is activated. The book can be found at http://www.maxwell.lambda.ele.puc-rio.br/livros.php\# along with the other two interactive books (Electric Circuits and Controls \& Servomechanisms). The three books are in Portuguese and published in Open Access.

The fifth and last type is the set o LOs.

At the moment, there are no LOs for all topics of the syllabus, but the other contents cover all of them. More LOs will be developed during the first semester of 2014.

All digital contents developed by PUC-Rio faculty/researchers/students are managed by the Maxwell System. The System has a library of links that indicates the links to contents (in Open Access) developed by other institutions, as for example the Rice University text book [7].

\section{C. $\quad$ Course Guide}

A course guide (roteiro) is under development. It is an html file that connects all course contents, activities, external links, etc. It has texts that explain topics and relate them to contents. There is one unit in the guide for each unit of the course.

\section{LOS, CMAPS AND THE COURSE GUIDE}

LOs have been developed with the objective of being reusable. They can be combined in different ways and some can be used in more than one course.

As mentioned in section IV, there is a guide for the Signals \& Systems Blended Learning course. LOs are some of the contents to be linked by guide.

The first unit of the course is Introdução - Conceitos Básicos de Sinais e Sistemas (Introduction - Basic Concepts of Signals and Systems).

Figure 2 shows the set of concepts in the CMap (v3) which belong to unit 1 of the course; they are painted green. It is important to remark that there is a concept (box) called Sampling and A/D \& D/A Converters that has been splitted in four LOs; this was because it became too big, as prevously mentioned.

It is also important to mention that two LOs that are not concepts (boxes) in the CMap are used in the guide. The Half-wave Rectifier - a Nonlinear System and The Fullwave Rectifier - a Nonlinear System are used to show nonlinear systems in the systems classification topic.

\section{LOS, CMAPS AND DIGITAL LIBRARIES}

Digital Libraries have been quite useful in managing shareable digital contents in general and courseware in particular [8, 9]. They allow digital contents to have "independent life", i.e., they can be searched, retrieved and used even when the user is not a student in the course. This happens if the authors yield access to other persons besides their students or even Open Access. At the same time, since they have "independent life", they are not limited to only a course / class - many curses / classes can share them without replication, making it easier to update when necessary.
CMaps have been used to automatically navigate contents on a digital repository. An example of such use is a project developed at Georgia Tech for a course on DSP - Digital Signal Processing [10, 11]. This project focuses in naviganting in a repository that already has contents on a certain subject.

The present work is concerned in defining a strategy to create LOs based on CMaps. Existing and future LOs are and will be managed by a Digital Library, but the objective is the opposite of $[10,11]-$ it is to populate the repository with LOs that are defined using CMaps.

The Maxwell System is also a repository that hosts many other digital contents (class notes, interactive books, lists of problems, etc) in the same areas of the LOs. For this reason, the work developed at Georgia Tech will be considered as a possible extension of this one.

All LOs are describe using a metadata set that includes DCMES - Dublin Core Metadata Element Set (http://www.dublincore.org/), ISO 15836/2003, and also many elements of IEEE LOM - Learning Object Metadata (http://ltsc.ieee.org/wg12/index.html).

The Maxwell System is an OAI-PMH - Open Archives Initiative Protocol for Metadata Harvesting (http://www.openarchives.org/) Data Provider. For this reason, all metadata that describe the LOs are open for harvesting by OAI-PMH Service Providers.

\section{COMMENTS AND NeXT STEPS}

The use od CMaps to define LOs in LTI Systems seems to be yielding good results. The development strategy has been modified to allow the Signals \& Systems Blended Learning course to include the LOs. This was necessary since this was an objective for the first semester of 2014.

Since other courses that deal with LTI Systems may be offered in the blended learning model, the existing LOs may be reused. Other LOs will be identified from the CMap as well as other "regions" will be defined to create guides for these other courses.

The problem of dealing with physical models, electrical and mechanical, must be addressed. The same happens with the properties; stability is a very important and long topic.

At the moment there seem to be two options. The first is to create related CMaps for each of these topics. This solution was used by Morse, Ibrahim and Williams [12] to analyze curricula. A second approach is to expand the current CMap as far as necessary, making it very broad in terms of coverage of LTI Systems with Electrical and Mechanical implementations. It will also be very complex. To deal with the complexity, views of "regions" could be created, as if subsets were focused with the remaining CMap ketp in background. It is important to remark that in the second solution, it is necessary to have boxes and links connecting all parts in the same "region".

Most probably both options will be tested and compared.

In the last semester of 2013 two follow ons started being addressed - the analysis of the structure of the courses on LTI Systems in Control \& Automation and Electrical Engineering curricula, and the extension of this analysis to the include the Mechanical Engineering curriculum. 
Since the first run of the blended learning version of Signals \& Systems will be over by the end of June 2014, the results in terms of underachievements will be computed and compared to the data of the last 10 semesters in the traditional model.

\section{ACKNOWLEDGMENT}

All CMaps in this work were created using Cmap Tools (http://cmap.ihmc.us/). This is a free product developed and made available by IHMC - Florida Institute for Human and Machine Cognition (http://www.ihmc.us/).

\section{REFERENCES}

[1] J. D. Novak and A. J. Cañas, "The theory underlying Concept Maps and how to construct and use them", Technical Report IHMC Cmap Tools 2006-1 Rev 01-2008, Florida Institute for Human and Machine Cognition, United States, 2008. Available http://cmap.ihmc.us/Publications/ResearchPapers/TheoryUnderlyi ngConceptMaps.pdf.

[2] IEEE LTSC - IEEE Standard for Learning Object Metadata. 1484.12.1-2002. Available http://tsc.ieee.org/wg12/index.html.

[3] C. D. Dziuban, J. L. Hartman and P. D. Moskal, "Blended Learning". EDUCAUSE Center for Applied Reasearch. Research Bulletin, vol. 2004, issue 7, United States, 2004. Available http://net.educause.edu/ir/library/pdf/erb0407.pdf.

[4] A. M. B. Pavani, "Concept Maps and Learning Objects - Part 1", Proceedings of the $4^{\text {th }}$ International Congress on Engineering Education, pp. 105-110, Malaysia, 2012. Available

[5] A. M. B. Pavani, "Concept Maps and Learning Objects - Part 2", Proceedings of the $1^{\text {st }}$ International Conference Society for Enginering Education, pp. 1-8, Portugal, 2013. Available http://dx.doi.org/10.1109/CISPEE.2013.6701980.

[6] F. Alonso, D. Manrique, L. Martínez and J. M. Viñes, "How Blended Learning Reduces Underachievement in Higher Education: an Experience in Teaching Computer Science", IEEE Transactions in Education, vol. 54, no. 3, 2011, pp. 471-478. Available http://dx.doi.org/10.1109/TE.2010.2083665.
[7] R. Baraniuk, Editor, "Signals and Systems", Connexions, Rice University, USA, 2013. Available http://cnx.org/content/ col10064/1.14/pdf.

[8] A. M. B. Pavani and A. L. S. Luckowiecki, Digital Libraries and Sharing Course Contents: the Maxwell System, in Proceedings of the 1999 ICECE - International Conference on Enginering and Computer Education, Rio de Janeiro, Brazil, 1999 (in CD ROM).

[9] R. M. Cardoso and A. M. B. Pavani, Sharing Course Contents: A Case Study, in Proceedings of the 2000 ICEE - International Conference on Enginering Education, ISSN 1562-3580, article WC5-1, Republic of China in Taiwan, 2000. Available http://www.ineer.org/Events/ICEE2000/Proceedings/c.htm.

[10] J. H. McClellan, L. D. Harvel, R. Velmurugan, M. Borkar and C. Scheib, "CNT: Concept-Map Bases Navigation and Discovery in a Repository of Learning Contents", Proceedings of the $34^{\text {th }}$ ASEE/IEEE Frontiers in Education Conference, pp. F1F-13-18, United States, 2004. Available http://dx.doi.org/10.1109/ FIE.2004.1408581.

[11] J. H. McClellan, M. Borkar, R. Velmurugan, L. D. Harvel and C. Scheib, "Concept-Map for Navigating Signal Processing Education Resources", Proceedings of the 2004 IEEE $11^{\text {th }}$ Digital Signal Processing Workshop and IEEE $3^{\text {rd }}$ Signal Processing Educational Workshop, pp. 1-5, United States, 2004. Available http://dx.doi.org/10.1109/DSPWS.2004.1437899.

[12] R. Morsi, W. Ibrahim and F. Williams, "Concept Maps: Design and Validation of Engineering Curricula", Proceedings of the $37^{\text {th }}$ ASEE/IEEE Frontiers in Education Conference, pp. T3H18-23, United States, 2007. Available http://dx.doi.org/10.1109/ FIE.2007.4418180.

\section{AUTHOR}

A. M. B. Pavani is with the Pontifícia Universidade Católica do Rio de Janeiro, Rio de Janeiro, RJ, 22451-900, Brazil (apavani@lambda.ele.puc-rio.br).

This article is an extended and modified version of a paper presented at the CISPEE 2013 conference, held October 31 - November 01, 2013, in Porto, Portugal. Article received February 02, 2014. Published as resubmitted by the author 07 March 2014. 
PAPER

CMAPS, LEARNING OBJECTS AND A BLENDED LEARNING SignAls \& SYSTEMS COURSE

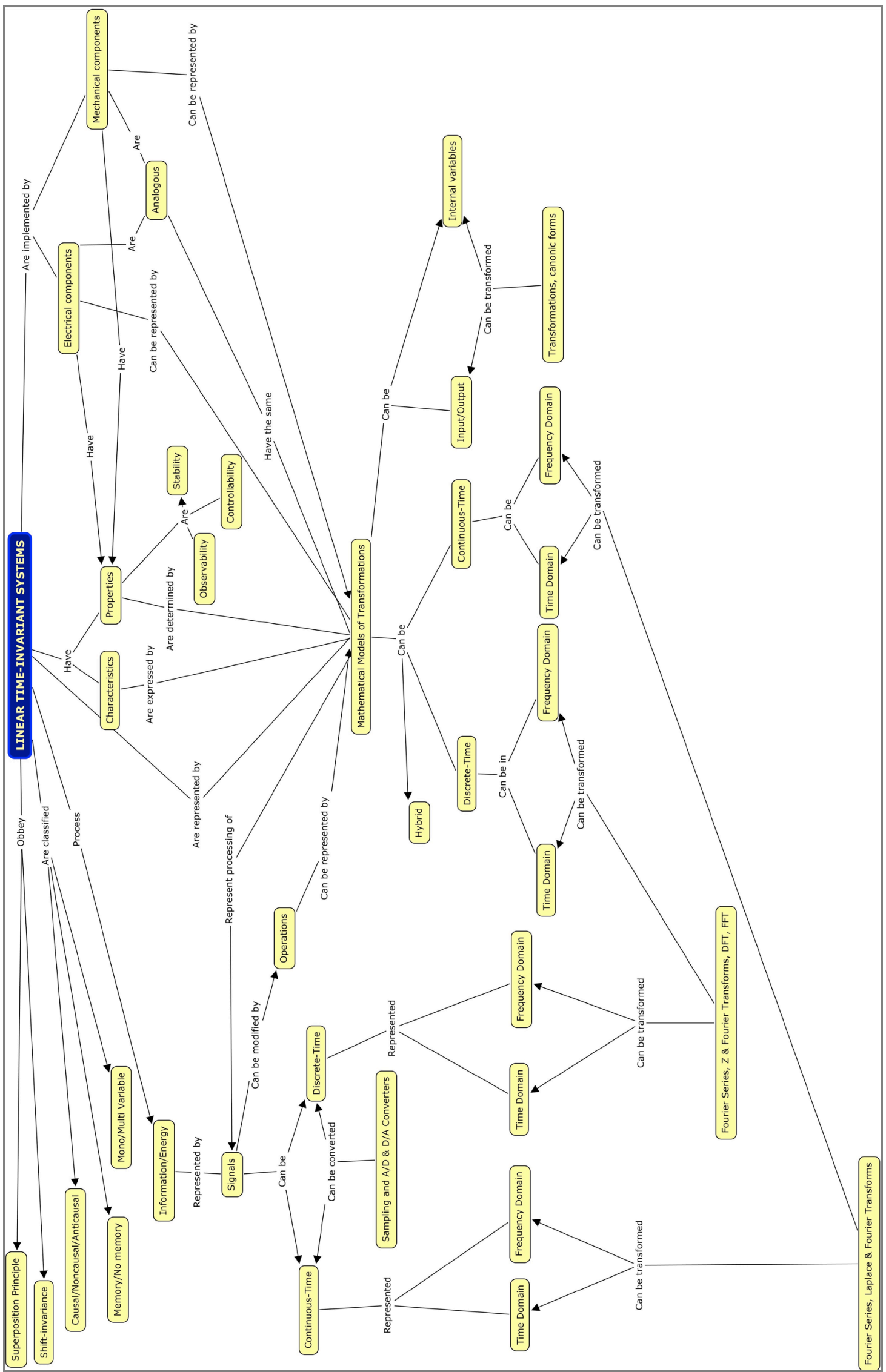

Fig. 1 - CMap (v3) for Linear Time-Invariant Systems. 
PAPER

CMAPS, LEARNING OBJECTS AND A BLENDED LEARNING SignAls \& SYSTEMS COURSE

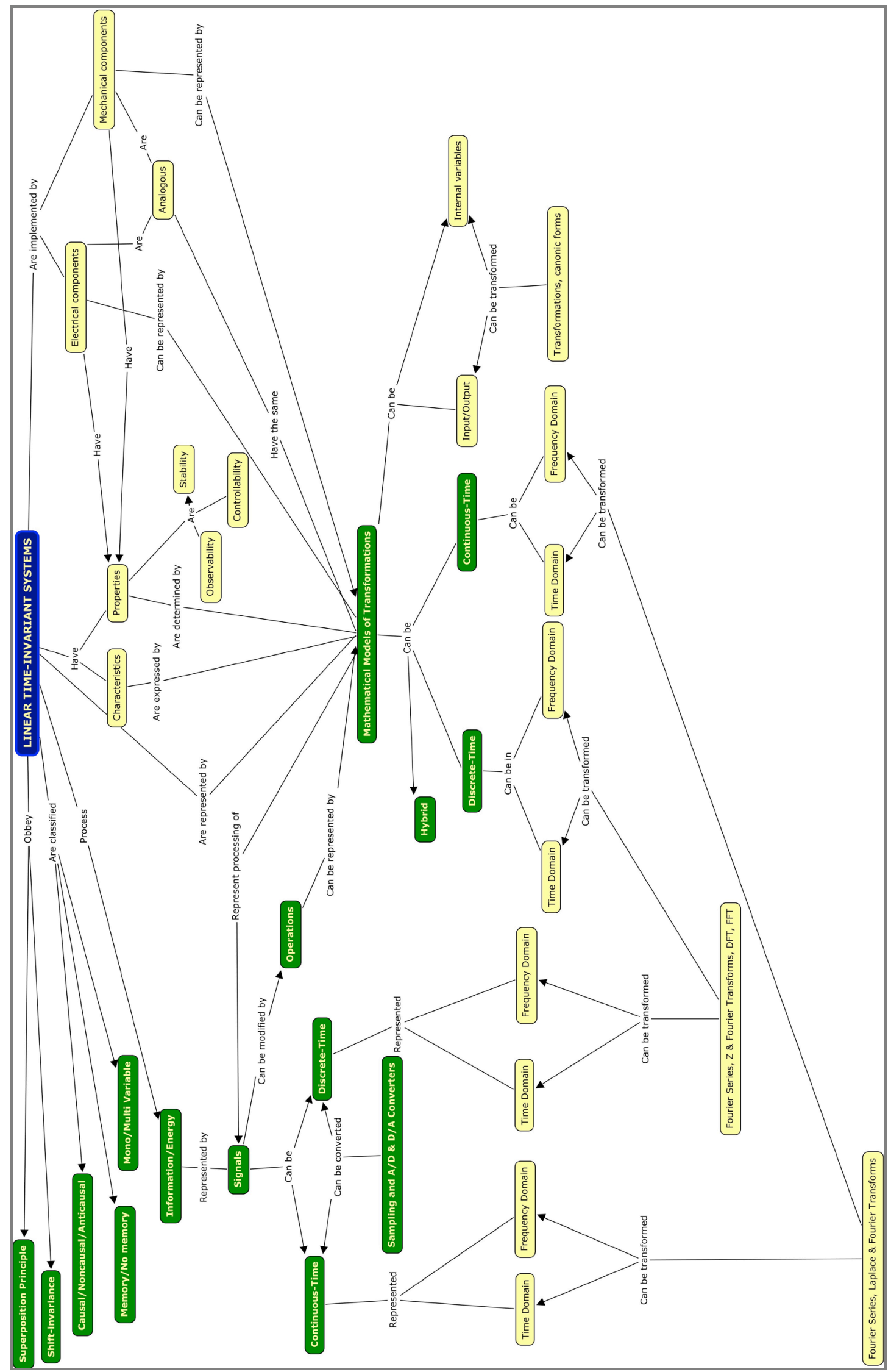

Fig. 2 - CMap (v3) for Linear Time-Invariant Systems Showing Region of Unit 1 of the Course Guide. 